MATEC Web of Conferences 40, 07005 (2016)

DOI: $10.1051 /$ matecconf/20164007005

(C) Owned by the authors, published by EDP Sciences, 2016

\title{
Research on Efficiency of Contactless Charging System based on Electromagnetic Induction
}

\author{
CHEN Jianshu ${ }^{1}$, LIU Xiulan ${ }^{1}$, CHI Zhongjun ${ }^{1}$, LI Xianglong ${ }^{1}$, JIAO Dongsheng ${ }^{1}$, ZENG Shuang ${ }^{1}$ \\ 1 State Grid Beijing Electric Power Research Institute, Fengtai District,Beijing 100075, China
}

\begin{abstract}
For the efficiency problem of contactless charging in type of electromagnetic induction, this paper establishes a mathematical model of contactless charging in type of electromagnetic induction and the theoretical derivation. This contactless charging simulation model is founded by Matlab/Simulink, which uses the frequency of PWM generator, the mutual inductance value of the coil and load resistance of RL to simulate some conditions, such as the working frequency in practical work, the distance of coil, whether the coils are directed at the central, and changing of loads. Then through the influence of the changing frequency, load and mutual inductance, contactless charging in type of electromagnetic induction is analyzed. By the whole simulation experiment on contactless charging, the theory deduced from the mathematical model is verified, and the method to improve inductive contactless charging is proved.
\end{abstract}

\section{Introduction}

Inductive contactless charging is also called contactless electromagnetic induction charging, which is currently the main contactless charging method adopts by electric vehicle[1], but the efficiency of power transmission is a main problem have to be solved in contactless charging technology field.

In order to meet the electric vehicle to the contactless power transmission, people begin an further research on inductive power transfer from the beginning of the last ninety century[2]. In abroad, Professor Boys's research team design out of the device for the power supply of electric vehicle in the harsh environment[3][4], its transmission efficiency is up to $75 \%$; The inductive contactless charging system of Magne-charge speed up the popularization and application of electric vehicle by effectively overcome the shortcomings of repeatedly plug and wire exposed[5]; Society of Automotive Engineers developed recommended practice for electric vehicle charging by use of inductive electric energy transmission technology in North America[6].Compared with foreign countries, the domestic research is late in the radio transmission filed, part of the domestic universities and research institutions have done a lot of work in the basic theory and application[7]-[9],[14][15], the present research focused on the control strategy and system design[10]-[14],the research on ICPT technology is worth mentioning, which is done by City University of Hong Kong and they mainly excogitate a general contactless charging platform[15]-[17], however the research aiming at power wireless transmission efficiency problem is seldom.
This paper uses Matlab/Simulink to establish the contactless charging system model to simulate the actual work frequency, coil distance change and load change condition and simulation, through regulation of PWM generator frequency, mutual inductor value, RL value of the load to research the frequency, load and mutual inductance coefficient effect on electromagnetic inductive contactless charging, verify the mathematical model deduced theory and proved the method of improve working efficiency.

\section{Inductive Contactless Charging System}

The core technology principle of inductive contactless charging is based on switching power supply[18], design of transformer part of the traditional switching power supply for two coils are separated, two coil form a detachable transformer by coupling coefficient between the coil to carry on contactless charging.

Power supply for contactless inductive charging system are high frequency alternating current, but its frequency range is relatively low to $20 \mathrm{kHz}-$ $5000 \mathrm{kHz}$.High frequency alternating current through the primary coil to form the magnetic field to transfer to the secondary coil and through the transformation of electrical energy supplied to the load by receiving the high-frequency magnetic field conversion $\mathrm{AC}$ power. A contactless inductive charging work schematic diagram shown as Fig.1. 
Advantages of the charging mode is its basic technology is more perfect and the electric energy can be output and control stability; In addition, because of its working frequency is relatively low, the transmission of power is so great that can fully meet the power requirements of electric vehicle charging. However, the presence of contactless inductive charging mode has problems as short charging distance, tolerate stagger from small coil, it makes the contactless induction charging has many limitations in the application of electric vehicles.

In this paper, EVs take the contactless inductive charging system as its charging mode due to the mode can meet the power requirements and its technology is relatively mature. For its shortcomings, this article through to optimized coil design, power compensation and dynamic load adaptive research to deliver results of high efficiency, long-distance, high-power.

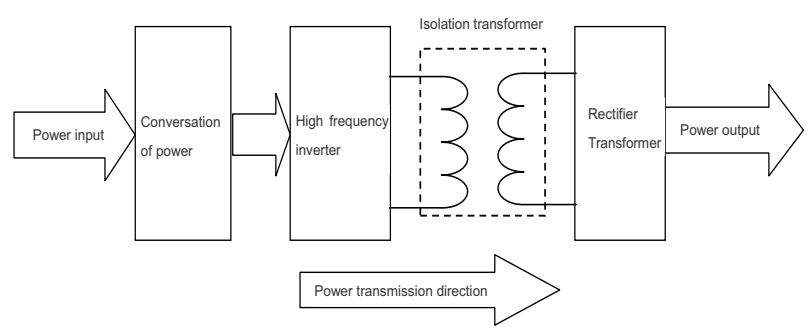

Fig. 1 Inductive Contactless Charging Work Schematic Diagram

\section{Inductive Contactless charging model}

Without considering the charging coil of the energy loss of the radiating portion, the body portion of the contactless EVs charging circuit represented by the equivalent circuit shown in Fig.2.Equivalent circuit for power supply is high-frequency $\mathrm{AC}$ power, two charging coils is equivalent to two transformer with mutual inductance ,respectively L1 and L2, the inductance value is $\mathrm{M}$, the equivalent coil resistance is two resistors R1, $\mathrm{R} 2[19][20]$.This paper is the study of the compensation method of PSSS type, the introduction of two capacitors $\mathrm{C} 1$ and $\mathrm{C} 2$ to the circuit for bilateral series compensation, to further improve the efficiency of it. Roughly equivalent with a pure resistive load RL for electric vehicle battery.

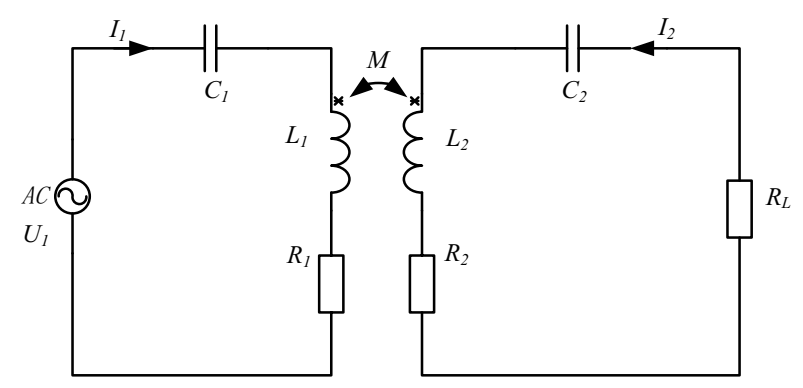

Fig. 2 Contactless Charging Circuit Equivalent Model
Mathematical analysis of the equivalent circuit, according to the KVL theorem are listed in the following equations and solved:

$$
\begin{gathered}
\mathrm{U}_{1}=\left(\mathrm{R}_{1}+j \omega \mathrm{L}_{1}+\frac{1}{j \omega \mathrm{C}_{1}}\right) \cdot \mathrm{I}_{1}+j \omega \mathrm{M} \cdot \mathrm{I}_{2} \\
0=j \omega \mathrm{M} \cdot \mathrm{I}_{1}+\left(\mathrm{R}_{\mathrm{L}}+\mathrm{R}_{2}+j \omega \mathrm{L}_{2}+\frac{1}{j \omega \mathrm{C}_{2}}\right) \cdot \mathrm{I}_{2}
\end{gathered}
$$

Resonance:

$$
\begin{aligned}
& j \omega L_{1}+\frac{1}{j \omega C_{1}}=0 \\
& j \omega L_{2}+\frac{1}{j \omega C_{2}}=0
\end{aligned}
$$

While the resonant case, both sides of the coil current can be obtained with solving the matrix equation as follows:

$$
\begin{aligned}
& I_{1}=\frac{\left(R_{2}+R_{L}\right) U_{1}}{R_{1}\left(R_{2}+R_{L}\right)+\omega^{2} M^{2}} \\
& I_{2}=\frac{j \omega U_{1}}{R_{1}\left(R_{2}+R_{L}\right)+\omega^{2} M^{2}}
\end{aligned}
$$

The transmission efficiency of the whole system:

$$
\eta=\frac{\omega^{2} \mathrm{M}^{2} \mathrm{R}_{\mathrm{L}}}{\mathrm{R}_{1}\left(\mathrm{R}_{2}+\mathrm{R}_{\mathrm{L}}\right)+\omega^{2} \mathrm{M}^{2}\left(\mathrm{R}_{2}+\mathrm{R}_{\mathrm{L}}\right)}
$$

With formula(5) can be obtained preliminary that efficiency of the charging system have positive correlation with AC power frequency(f),mutual inductance(M) between former side and vice side coil .In addition, there is a certain relationship with the load resistance value. Seeking the partial derivative of the formula (7) with load resistor RL:

$$
\mathrm{d} \eta / \mathrm{dR}_{\mathrm{L}}=0
$$

The formula (8) can obtain the best matching relation between the load and the efficiency:

$$
R_{L_{\text {matched }}}=\sqrt{\mathrm{R}_{2}^{2}+\omega^{2} \mathrm{M}^{2} \cdot \mathrm{R}_{2} / \mathrm{R}_{1}}
$$

By formula (7), (9) shows, transformer, and system Realization of the best system efficiency has a direct relationship with the working frequency, mutual inductance value and the coil load resistance, the relationship between how well matched the three is a key problem of efficiency optimization.

\section{Example Analysis}

The example system uses a BOOST circuit as three-phase rectifier which output voltage adjustable to get the DC output voltage needed, using a BUCK circuit as stepdown circuit which input signal controllable, the entire contactless inductive charging system simulation model shown as Fig.3. 


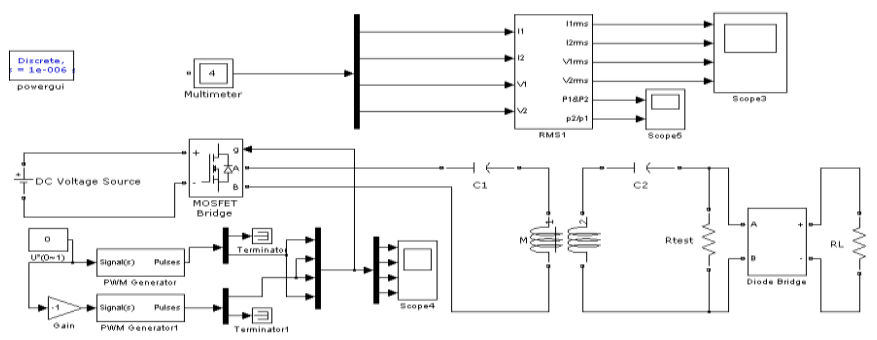

Fig. 3 Inductive Contactless Charging System Simulation Mode

The simulation system used transformer coil model with software to simulate the primary side and secondary side for contactless charging system, build a front-end circuit of adjustable frequency inverter for DC voltage source and rectifying alternating current for the rear-end circuit. Through adjusting the frequency of the PWM generator, mutual values of the coil and the load resistance RL to simulate actual working frequency, coil distance, whether changes in the coil and the load change conditions.

Setting circuit work at DC voltage of $50 \mathrm{~V}$, mutual inductance value is $\mathrm{M}=30 \mu \mathrm{H}$, coil inductance L1 $=\mathrm{L} 2=110$ $\mu \mathrm{H}$, resonant capacitance is $0.1 \mu \mathrm{F}$.

\subsection{Frequency on contactless inductive charging efficiency}

From the frequency point of view, when the system working frequency in the vicinity of the resonance frequency, the charging system reach to a higher efficiency[20].In the simulations, a resonant capacitor set different capacitance values, coil inductance value remains constant, we get three groups of different resonant frequency. Adjust the frequency size, we get three groups of efficiency curve as shown in figure 4.

It can be obtained that under different resonant frequency, capacitance value is different. Through by compared different groups we see that the resonant frequency is high, the efficiency is greater. In Fig.4, there is a small increase of two curves for which resonant frequency is $48 \mathrm{kHz}$ and $67 \mathrm{kHz}$ at low frequencies, which is caused by harmonic of AC voltage signal under the low frequency.

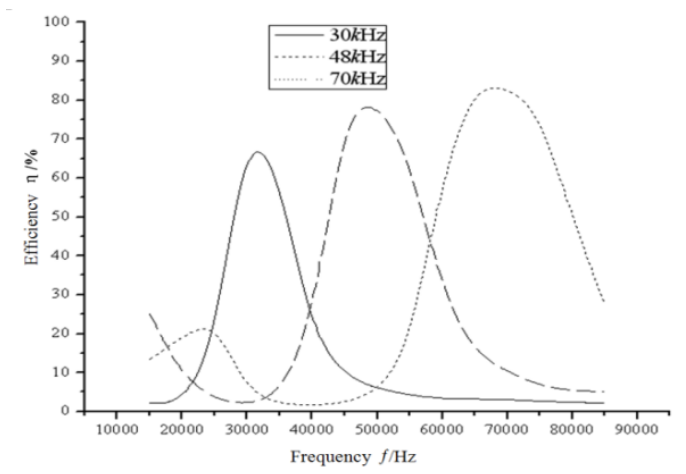

Fig. 4 Influence of Frequency Variation on System Efficiency

As shown in Fig. 5 we can better see the change trend of the efficiency by matching different capacitance values at the resonant frequency: the greater the resonant frequency, the higher the efficiency.

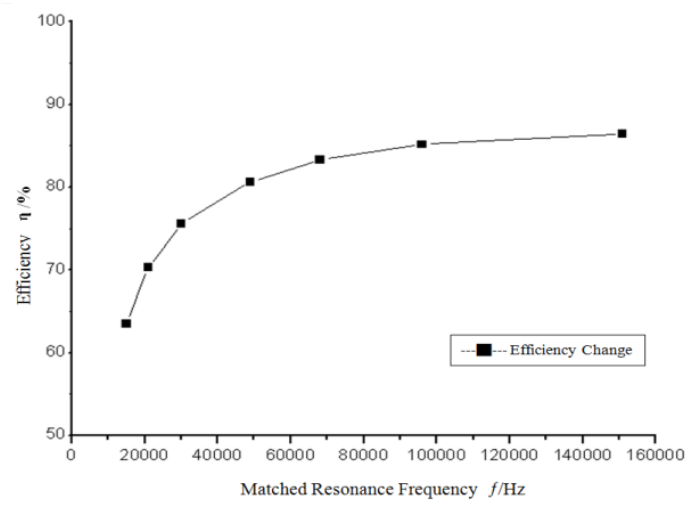

Fig. 5 Influence of Different Resonant Frequency on System Efficiency

\subsection{Load on contactless inductive charging efficiency}

Variation of the load will also have a great effect on the efficiency, the setting of different load value of RL changes in the $0.1 \Omega \sim 500 \Omega$, in this paper simulation experiment is carried out in matching three groups of different resonant frequency. As shown in Fig.6, the change trend of the efficiency of the system when the load changes.

When the load in the vicinity of the best matched load resistance values can achieve optimal efficiency, when the load is too small or too large, efficiency can reach about $30 \%$. It can be speculated that in more extreme cases, such as the side load short circuit or open circuit conditions, efficiency will decrease to 0 .As can be seen in Figure 6,higher the frequency, the greater efficiency.

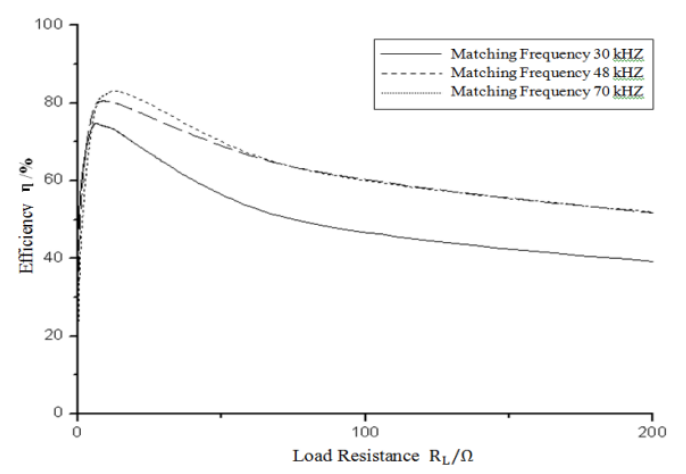

Fig. 6 Influence of Different Load on System Efficiency

\subsection{Mutual inductance on contactless inductive charging efficiency}

There are many cases will lead to the mutual inductance between the two coils to drop in value while the contactless charging system is in practical application, such as the coil not to accurately, the distance between the coils change, and the change mutual inductance will directly affect efficiency of the charging system. In this paper we set the mutual inductance $M$ changes in 
$5 \mu \mathrm{H} \sim 50 \mu \mathrm{H}$ interval and perform two sets of simulation experiments to respectively simulate the distance change between the coil real-time effect on the efficiency and the different coil design on the efficiency, in the first set of experiments not matching the load resistance and the second groups matching the load resistance.

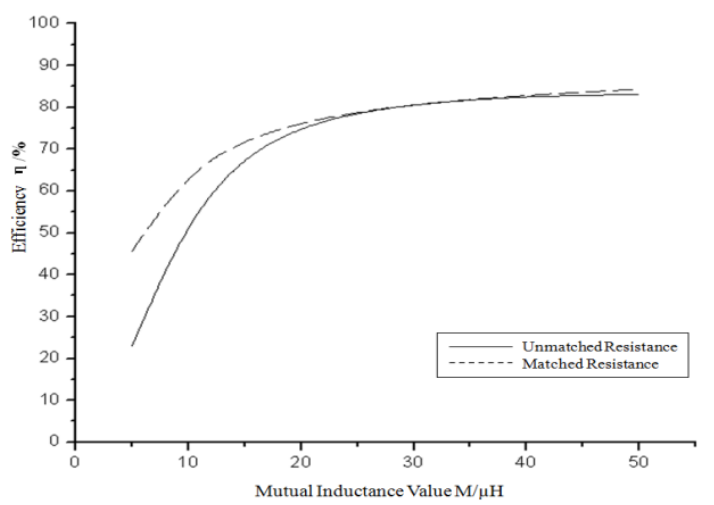

Fig. 7 Influence of Distance Variation on System Efficiency

As shown in Fig.7, two curves are respectively not matching load resistance and matching load resistance for efficiency change. The change of transformer and the efficiency have positive correlation, namely the transformer becomes larger, the efficiency is higher. In addition that efficiency increase more significantly with transformer for which set matching the load resistance.

\section{Conclusion}

This paper establishes the mathematical model of induction type for contactless power transmission, through by verification calculation and simulation experiment, obtains a close relationship between efficiency of inductive contactless charging system and system frequency, the value of mutual inductance coil, the rear end of equivalent load value, the relationship as follows:

First, the working frequency of system is bigger, the working efficiency is higher, the working efficiency of system is determined by the inverter circuit which involves the high frequency design.

Second, mutual inductor between the coil has the positive correlation with the efficiency of system, the bigger of mutual inductance value and degree of coupling coil is, the higher working efficiency of the system is. Therefore, the optimization design of induction contactless charging electric power transmitting coil is one of the key link to improve the work efficiency of the system.

Third, the optimal working point of inductive contactless charging system corresponds to an optimal matching load value, and only the equivalent resistance of back-end of the system is same or close to the best matching load value, the working efficiency will get to the highest, so the research on how to match the back-end equivalent load value is another key to study the inductive contactless charging system.
Therefore, we can be studied the optimization design of coil, power compensation and adaptive dynamic load in the future.

\section{References}

1. Junji Hirai, Tae-Woong Kim, Atsuo Kawamura. Study on Intelligent Battery Charging Using Inductive Transmission of Power and Informatio. IEEE Transactions on Power Electronics, 2000, vol15, No.2, pp. 335-345.

2. Du Weitong. Series Lithium-ion Batteries Rapid Charging Technology with the Contactless Power Transfer Technology[D]. Chongqing: Chongqing University, 2012.

3. G. A. J. Elliott, J. T. Boys, A. W. Green. Magnetically Coupled Systems for Power Transfer to Electric Vehicles. IEEE Catalogue, 2004, 95 (5): 797-801.

4. C. S. Wang, O. H. Stielau, G. A. Covic. Design Considerations for a Contactless Electric Vehicle Batter Charger. IEEE Transactions on Industrial Electronics, 2005, 52 (5): 1380-1314.

5. N. H. Kutkut, K. W. Klontz. Design Considerations for Power Converters Supplying the SAEJ-1773 Electric Vehicle Inductive Coupler. IEEE APEC 1997, 1 (2): 841-847.

6. Society of Automotive Engineers. SAE Electric Vehicle Inductive Coupling Recommended Practice. SAE J-1773, Issued 1995-01, Revised 1999-11.

7. Sun Yong, Lou Peihuang, Wu Liangliang. Research on Application Platform of Contactless Supply System[J]. Industrial Control Computer, 2009(3): 8688.

8. Lin Ning, Yao Yingying. Design of a Wireless Energy Transfer System with Constant Output[J]. Power Electronics, 2011(2): 86-88.

9. Zhu Chunbo, Liu Kai, Yu Chunlai, et al. Simulation and experimental analysis on wireless energy transfer based on magnetic resonance[C]. 2008 IEEE Vehicle Power and Propulsion Conference, 2008: 1-4.

10. Li Jiangui, Chen HaiYan, Yang Qingxin, et al. Study of Detachable Transformer for Contactless Energy Transmission System[J]. Transactions of China Electrotechnical Society, 2007, 22(1): 107-110.

11. Sun Yue, Chen Guodong, Dai Xin, et al. A Constant Current Control Method for Contactless Power Transmission System[J]. Journal of Chongqing University, 2008, 31(7): 766-769.

12. Dai Xin, Sun Yue, Su Yugang, et al. Study on Contactless Power Bi-directional Push Mode[J]. Proceedings of the CSEE2010, 30(18): 55-61.

13. Han Teng, Zhuo Fang, Liu Tao, et al. Contactless Power Transfer System Using Isolation Transformer[J].Power Electronics, 2004, 38(5): 28 29.

14. Zhao Xiaokun. The Research on the Technology of Electric Vehicle Inductive Charging[D]. Harbin: Harbin Institute of technology, 2009. 
15. Zhou Wenqi. Research on Characteristic and Design of Inductively Coupled Power Transfer System[D]. Hanzhou: Zhejiang University, 2008.

16. Y. R. Hul, W. C. H. Wing. A new generation of universal contactless battery charging platform for portable consumer electronic equipment[C] . IEEE PESC 2004: 638-644.

17. X. Liu, S. Y. (Ron)Hul. Optimal design of a hybrid winding structure for planar contactless battery charging platform[J]. IEEE Trans on Power Electronics, 2008, 23(1): 455-463.

18. Kutkut, N. H, Klontz, K. W. Design considerations for power converters supplying theSAE J-1773 electric vehicle inductive coupler. IEEE APEC 1997, vol. 2, pp. 841-847.

19. Huang Xueliang, Tan Linlin, Chen Zhong, et al. Review and Research Progress on Wireless Power Transfer Technology[J]. Transactions of China Electrotechnical Society, 2013, 28(10): 1-11.

20. Zhao Zhengming, Zhang Yiming, Chen Kainan, et al. New Progress of Magnetically-coupled Resonant Wireless Power Transfer Technology[J]. Proceedings of the CSEE, 2013, 33(3): 1-13. 